PO027

\title{
RELATIONSHIP BETWEEN COLOUR RENDERING INDICES AND SUBJECTIVE COLOUR DIFFERENCES
}

\author{
Kenji Mukai
}

DOI 10.25039/x46.2019.PO027

from

CIE x046:2019

\author{
Proceedings \\ of the \\ 29th CIE SESSION \\ Washington D.C., USA, June 14 - 22, 2019 \\ (DOI 10.25039/x46.2019)
}

The paper has been presented at the 29th CIE Session, Washington D.C., USA, June 14-22, 2019. It has not been peer-reviewed by CIE.

(c) CIE 2019

All rights reserved. Unless otherwise specified, no part of this publication may be reproduced or utilized in any form or by any means, electronic or mechanical, including photocopying and microfilm, without permission in writing from CIE Central Bureau at the address below. Any mention of organizations or products does not imply endorsement by the CIE.

This paper is made available open access for individual use. However, in all other cases all rights are reserved unless explicit permission is sought from and given by the $\mathrm{CIE}$.

CIE Central Bureau

Babenbergerstrasse 9

A-1010 Vienna

Austria

Tel.: +4317143187

e-mail: ciecb@cie.co.at

www.cie.co.at 


\title{
RELATIONSHIP BETWEEN COLOUR RENDERING INDICES AND SUBJECTIVE COLOUR DIFFERENCES
}

\author{
Mukai, K. ${ }^{1}$ \\ ${ }^{1}$ Panasonic Corporation, Kadoma, Osaka, JAPAN \\ mukai.kenji@jp.panasonic.com
}

DOI 10.25039/x46.2019.PO027

\begin{abstract}
CIE recommends $R_{\mathrm{a}}$ and $R_{\mathrm{i}}$ as indices of colour rendering properties in CIE13.3. But $R_{\mathrm{a}}$ and $R_{\mathrm{i}}$ have some problems to be considered. CIE224 was published to solve the problems above. But even the proposed index $R_{\mathrm{f}}$ has some technical issues to be considered, and $R_{\mathrm{f}}$ is not a replacement of $R_{\mathrm{a}}$ neither for the purpose of rating and specification of products nor for regulatory or other minimum performance requirements.

In order to evaluate $R_{\mathrm{f}}$ a series of experiments comparing the correlation of $R_{\mathrm{f}}$ and $R_{\mathrm{a}}$ with the subjective colour differences was conducted. And it was made clear that both $R_{\mathrm{a}}$ and $R_{\mathrm{f}}$ are well correlated with the subjective colour differences. But under some illuminants, subjective colour difference is not same even if $R_{\mathrm{f}}$ is equivalent, and subjective colour difference is same even if $R_{\mathrm{f}}$ is not equivalent. These results are not seen in the case $R_{\mathrm{a}}$. The calculated colour differences that is base of $R_{\mathrm{a}}$ and $R_{\mathrm{f}}$ are well correlated with the subjective colour differences but the slope of the regression line between the calculated and the subjective colour differences is different by the Test Colour Sample.
\end{abstract}

Keywords: Colour Rendering Index, Subjective Colour Difference, Calculated Colour Difference

\section{Introduction}

Problems of $R_{\mathrm{a}}$ or $R_{\mathrm{i}}$ has been pointed out for long years, for example CIE 1964 Uniform Colour Space that is used to calculate the colour difference is outdated, the 14(15 in Japan) test colour samples may not be enough. Some technical committees did not change the recommended index of colour rendering from $R_{\mathrm{a}}$ and $R_{\mathrm{i}}$ although they tried to change hard. In 2017 CIE TC1-90 published CIE224 "CIE 2017 Colour Fidelity Index for accurate scientific use". But $R_{\mathrm{f}}$ that is proposed as a general colour fidelity index is not a replacement of $R_{\mathrm{a}}$ neither for the purpose of rating and specification of products nor for regulatory or other minimum performance requirements. CIE224 mentions that replacement of the CRI will be a matter of future study and discussion that will include the evaluation of $R_{\mathrm{f}}$.

As a result of evaluation of $R_{\mathrm{f}}$, it was reported that $R_{\mathrm{f}}$ changes very sensitively by the shift of peak wavelength of blue LED composing white LED (Smet et al., 2016). It has not made clear by experiments if the shifts of $R_{\mathrm{f}}$ match with the subjective colour differences. And it was reported that both of $R_{\mathrm{a}}$ and $R_{\mathrm{f}}$ are well correlated with subjective colour fidelity (Gu et al., 2017).

A series of experiments was conducted to investigate which Colour Rendering Index, $R_{\mathrm{a}}$ or $R_{\mathrm{f}}$ is well correlated with subjective colour difference.

\section{Methodology}

\subsection{Experimental setup}

The experiment was conducted by using 2 lighting booths that can make various spectral power distributions. The size of the both booth was $\mathrm{W} 2,2 \mathrm{~m} \times \mathrm{D} 2,4 \mathrm{~m} \times \mathrm{H} 2,2 \mathrm{~m}$. One booth was illuminated by the reference illuminant and the other one was illuminated by the test illuminant. The colour temperature of both illuminant was $3000 \mathrm{~K}$ and duv was $0 . R_{\mathrm{a}}$ and $R_{\mathrm{f}}$ of the reference illuminant was 96 and $95 . R_{\mathrm{a}}$ and $R_{\mathrm{f}}$ of the 11 test illuminants are shown in Table 
1 and Figure 1, the spectral power distributions are shown in Figure 2. Some test illuminants had equivalent $R_{\mathrm{a}}$ and different $R_{\mathrm{f}}$, some had different $R_{\mathrm{a}}$ and equivalent $R_{\mathrm{f}}$. The same 20 test colour samples, dummies of vegetable, flower and plants were set on the same tables put in the both booths. The spectral reflectance of the test colour samples are shown in Figure 3.

Table $1-R_{\mathrm{a}}$ and $\boldsymbol{R}_{\mathrm{f}}$ of the reference and the test illuminants

\begin{tabular}{|l|l|}
\hline & $\left(R_{\mathrm{a}}, R_{\mathrm{f}}\right)$ \\
\hline Reference Illuminant & $(96,95)$ \\
\hline \multirow{2}{*}{ Test Illuminants } & $\begin{array}{l}(96,95),(80,81),(85,84),(80,74),(84,84),(92,92), \\
(94,93),(68,74),(85,89),(80,84),(92,90)\end{array}$ \\
\hline
\end{tabular}

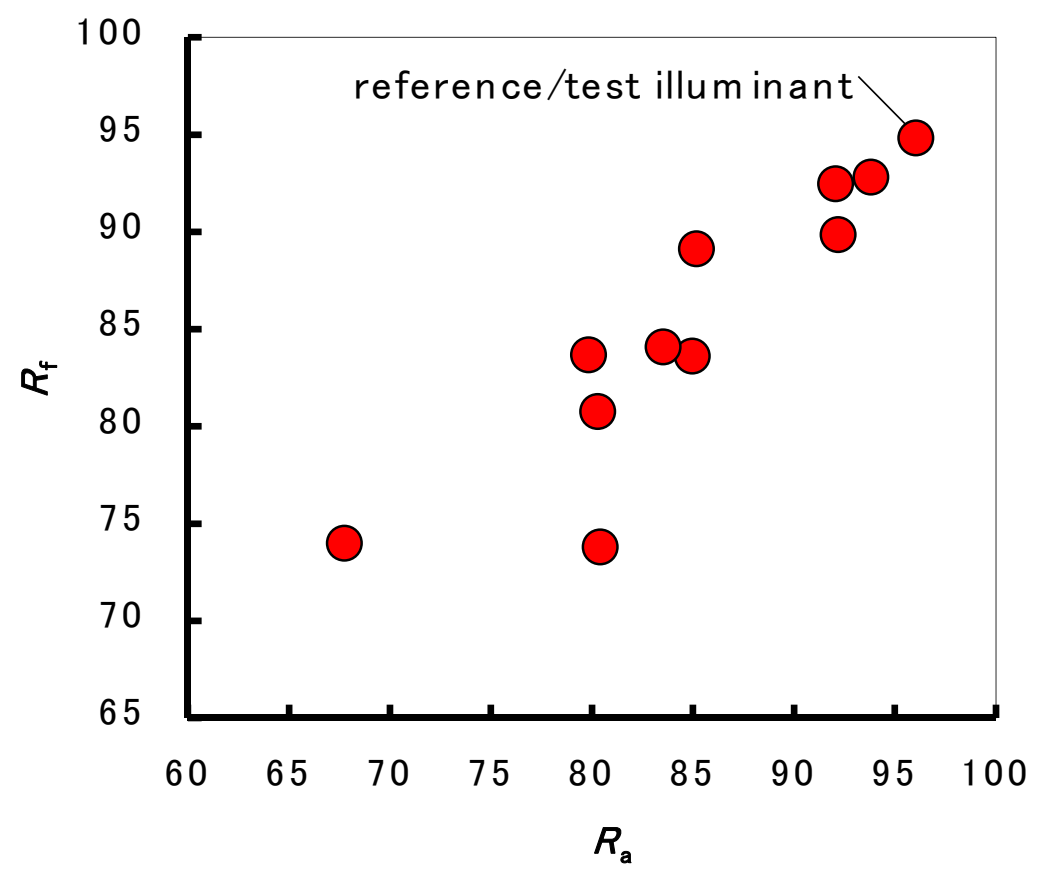

Figure $1-R_{\mathrm{a}}$ and $\boldsymbol{R}_{\mathrm{f}}$ of the reference and the test illuminants

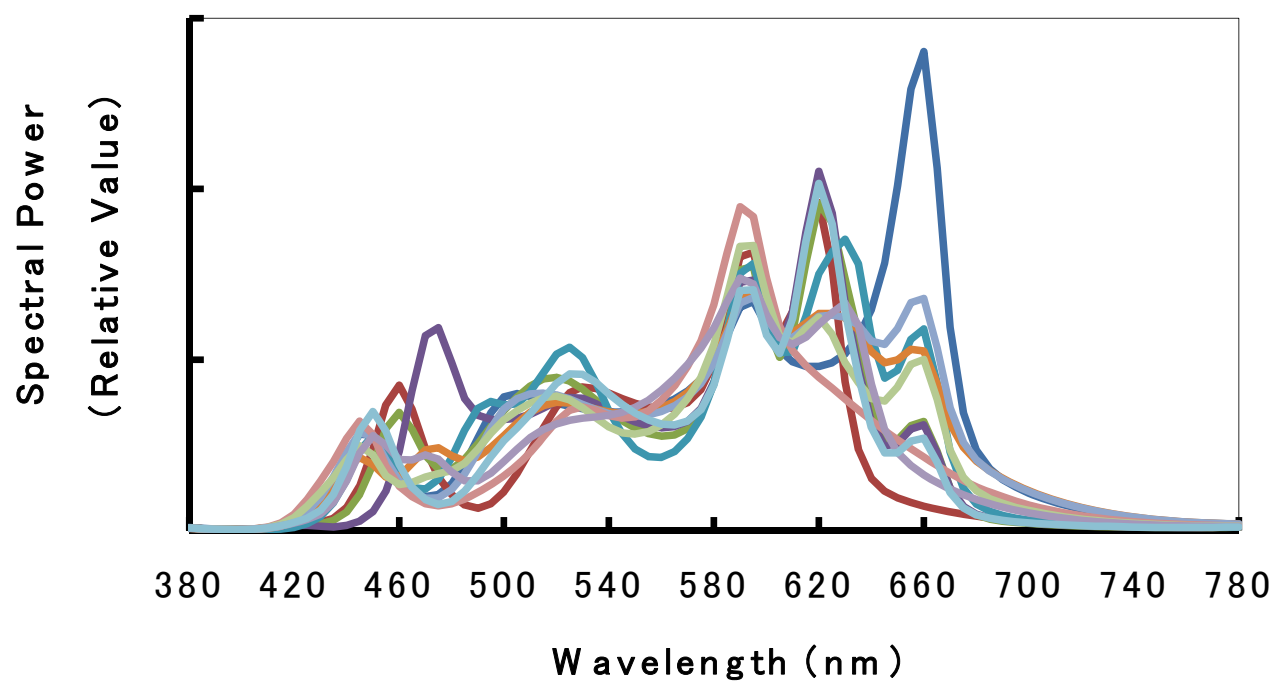

Figure 2 - Spectral power distributions of the reference and the test illuminants 


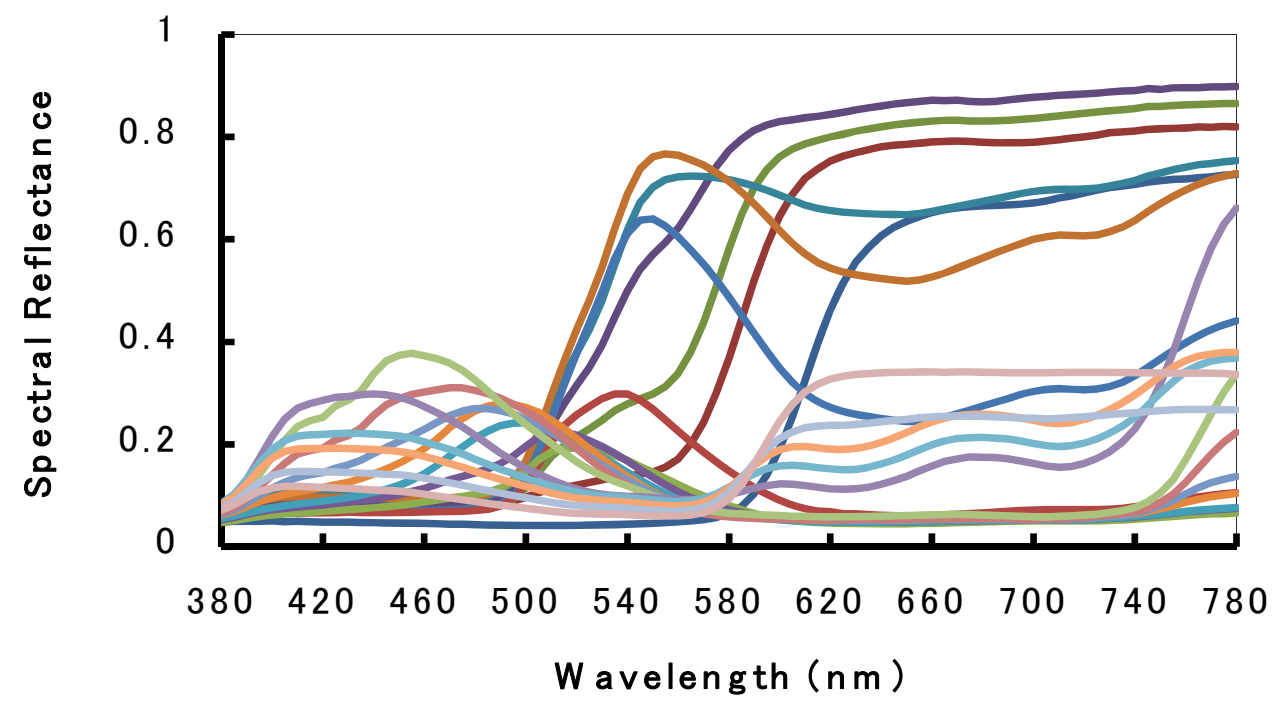

Figure 3 - Spectral reflectance of the test colour samples

The appearance of the pair of the lighting booths is shown in Figure 4, and test colour samples and dummies on the tables are shown in Figure 5.

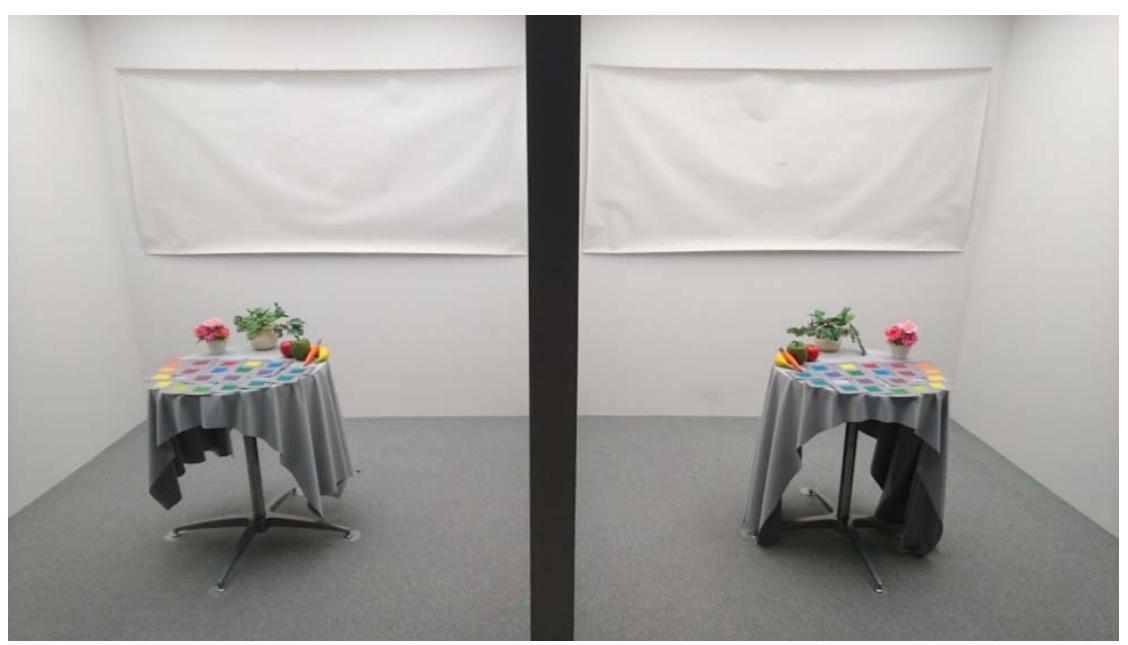

Figure 4 - Appearance of the pair of the lighting booths

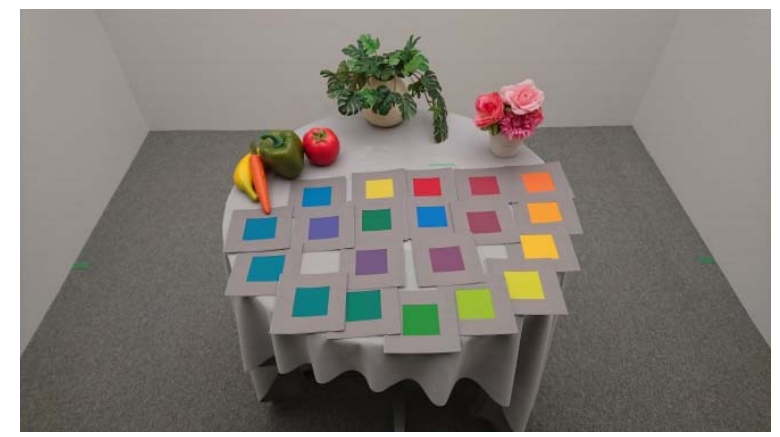

Figure 5 - Appearance of the test colour samples and dummies on the table 


\subsection{Procedure}

Subjects stood in front of the booths just centre of them and observed the test colour samples and dummies on the tables. First, the subject answered only the subjective colour difference of the red colour samples between two booths. Second, he/she answered the difference of yellow samples. Next, green samples and next, blue. And finally, he/she answered the subjective colour differences of all 20 colour samples and dummies on the tables comprehensively. He/she answered the colour difference according to the rating scale shown in Table 2. In the preliminary experiment the subjects answered the colour difference between 2 booths according to the difference of the gray scale, but the answers were not staible because it was difficult to convert the chromatic colour difference into achromatic difference for the subjects who were not experts of colour science.

Table 2 - Rating scale

\begin{tabular}{|c|l|}
\hline Scale & \multicolumn{1}{|c|}{ Description } \\
\hline 0 & No different \\
\hline 1 & Somehow different \\
\hline 2 & Slightly different \\
\hline 3 & Clearly different \\
\hline 4 & Considerably different \\
\hline 5 & Absolutely different \\
\hline
\end{tabular}

\subsection{Subjects}

6 women and man subjects with normal colour vision participated in the experiment. The experiment was repeated 3 times for one subject.

\section{Results}

\section{1 $R_{\mathrm{a}}, \boldsymbol{R}_{\mathrm{f}}$ and the subjective colour difference}

The relationship between $R_{\mathrm{a}}, R_{\mathrm{f}}$ and the subjective colour difference are shown in Figure 6 and Figure 7. The subjective colour difference is the average of 18 comprehensive answers of 6 subjects. Both of $R_{\mathrm{a}}$ and $R_{\mathrm{f}}$ are well correlated with the subjective colour difference. The correlation coefficient between $R_{\mathrm{a}}$ and the subjective colour difference is $-0,88$ and that between $R_{\mathrm{f}}$ is $-0,76$. The correlation coefficient value with $R_{\mathrm{a}}$ is higher although there is no statistical significant difference.

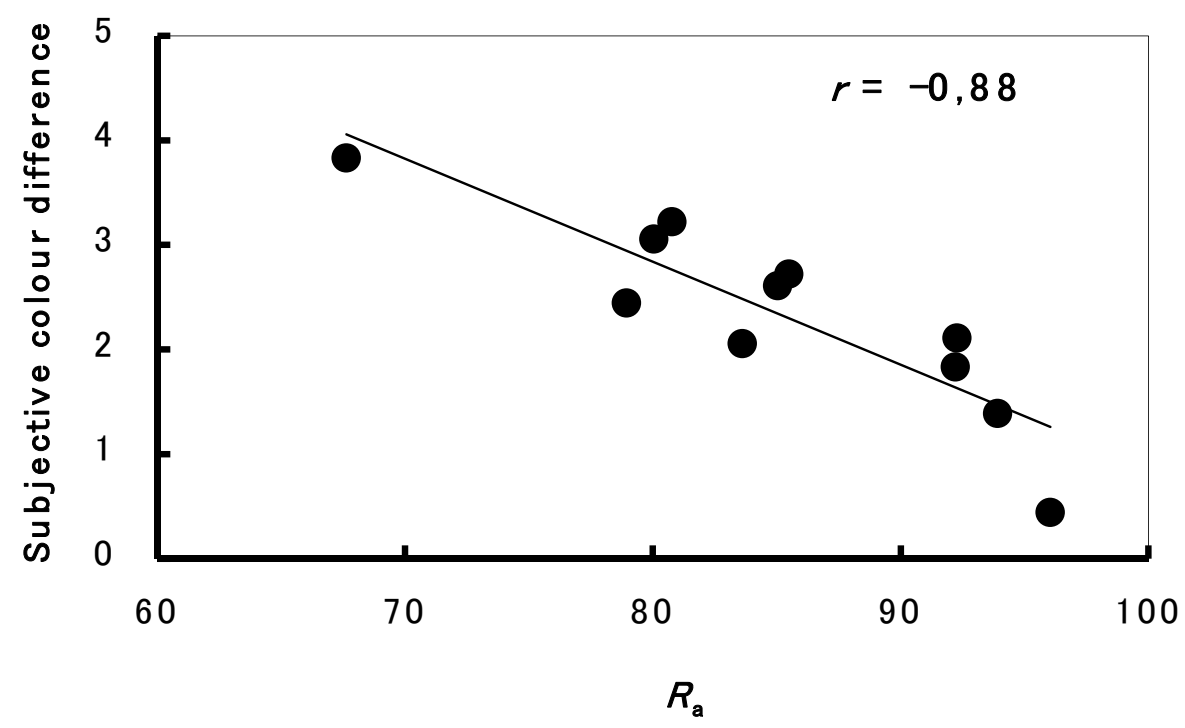

Figure 6 - Relationship between $R_{\mathrm{a}}$ and the subjective colour difference 


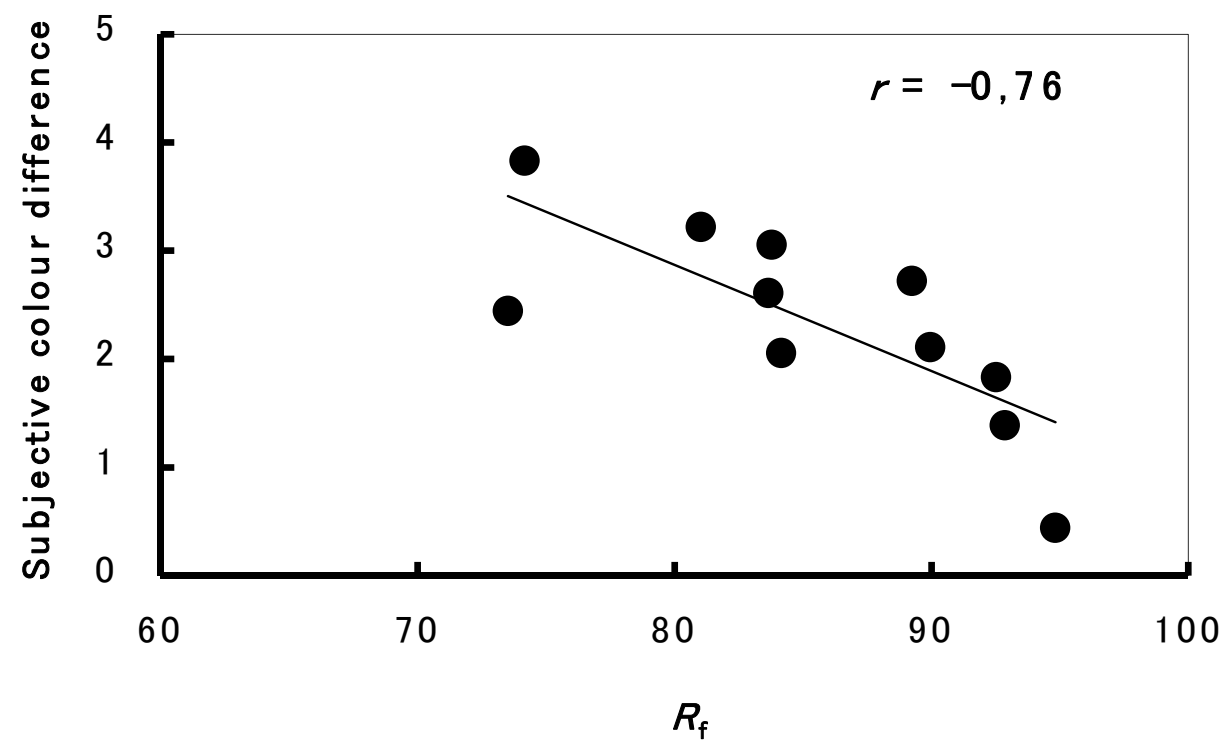

Figure 7 - Relationship between $R_{\mathrm{f}}$ and the subjective colour difference

\subsection{Comparison of the results between the conditions $R_{\mathrm{a}}$ or $\boldsymbol{R}_{\mathrm{f}}$ is equivalent}

As mentioned both of $R_{\mathrm{a}}$ and $R_{\mathrm{f}}$ are well correlated with the subjective colour difference. To investigate which index fits the subjective colour difference better, the results of equivalent $R_{\mathrm{a}}$ or $R_{\mathrm{f}}$ were compared. The relationship between $R_{\mathrm{a}}, R_{\mathrm{f}}$ and the subjective colour difference in case of equivalent $R_{\mathrm{f}}$ is shown in Figure 8. The subjective colour difference is the average of 18 comprehensive answers of 6 subjects. The larger $R_{\mathrm{a}}$ is, the smaller the subjective colour differences tend to be even if $R_{\mathrm{f}}$ is equivalent.
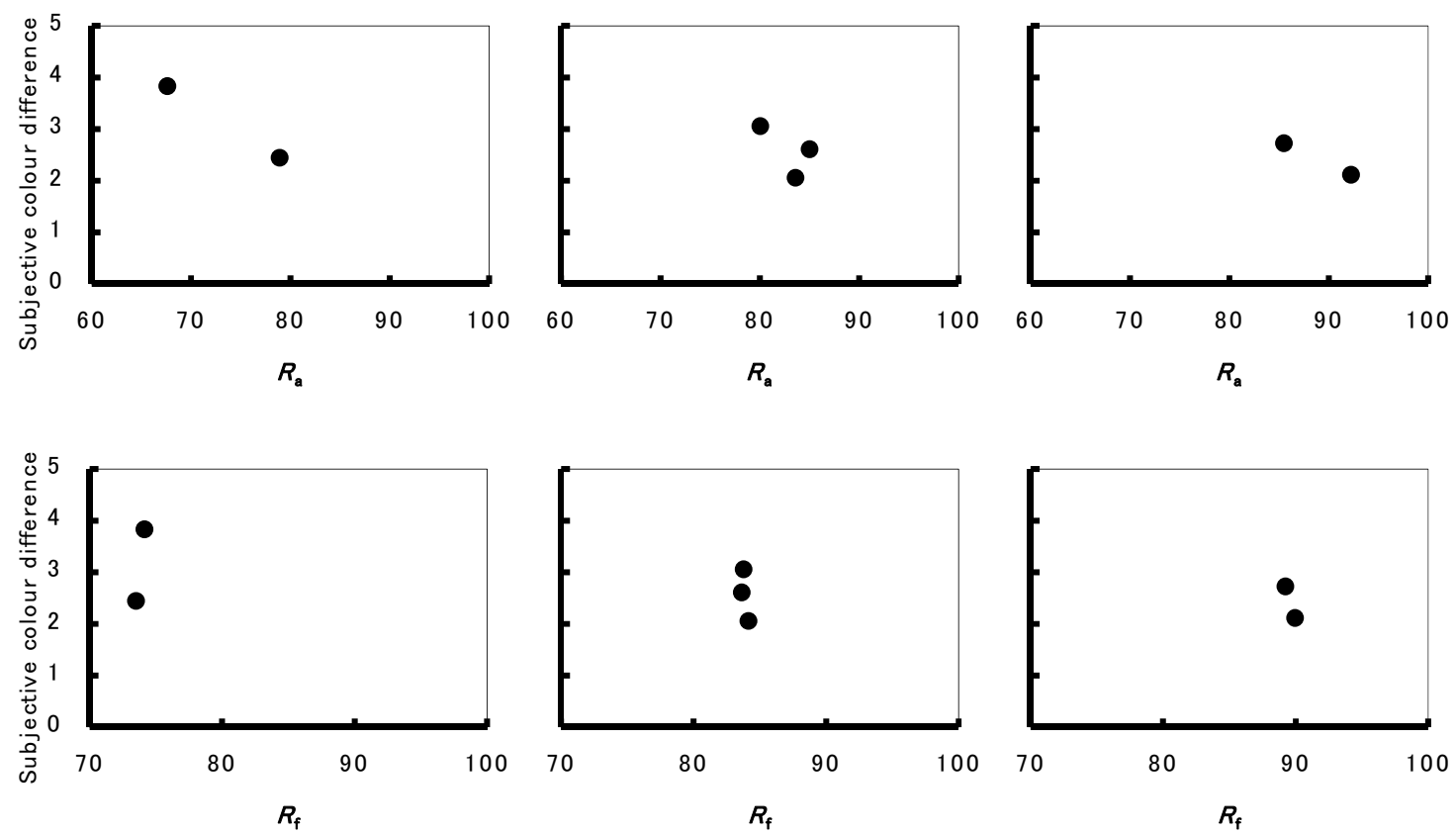

Figure 8 - Relationship between $R_{\mathrm{a}}, \boldsymbol{R}_{\mathrm{f}}$ and the subjective colour difference in case $\boldsymbol{R}_{\mathrm{f}}$ is equivalent

The relationship between $R_{\mathrm{a}}, R_{\mathrm{f}}$ and the subjective colour difference in case of equivalent $R_{\mathrm{a}}$ is shown in Figure 9. The subjective colour differences tend to be equal if $R_{\mathrm{a}}$ is equivalent, even if $R_{\mathrm{f}}$ is various. 

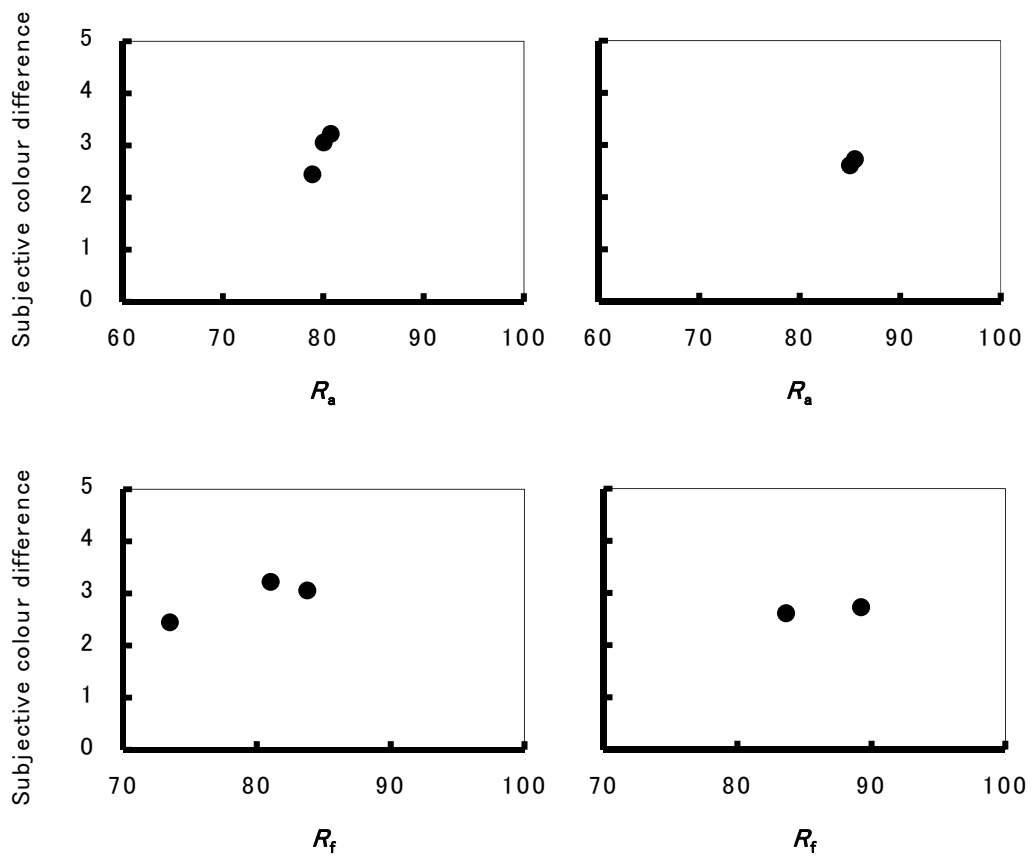
Figure 9 - Relationship between $R_{\mathrm{a}}, R_{\mathrm{f}}$ and the subjective colour difference in case $R_{\mathrm{a}}$ is
equivalent

As indicated above, $R_{\mathrm{a}}$ fits the subjective colour difference better than $R_{\mathrm{f}}$ although there are no statistical significant differences.

\subsection{Measured colour difference and the subjective colour difference}

The reference illuminant has very high $R_{\mathrm{a}}$ and $R_{\mathrm{f}}$ but it is not a standard illuminant. So it is not the best way to investigate the relationship between the subjective colour difference and the indices $R_{\mathrm{a}}$ or $R_{\mathrm{f}}$. To investigate which index fits the subjective colour difference better, it is better way to compare the relationship between the measured and calculated colour differences on the colour spaces used to calculate the indices $R_{\mathrm{a}}$ and $R_{\mathrm{f}}$ and the subjective colour differences.

The relationship between measured and calculated colour difference on CIE 1964 uniform colour space that is used to calculate $R_{\mathrm{a}}$ and the subjective colour difference is shown in Figure 10. The calculated colour difference (the horizontal axis) is the average of 20 test colour samples and the subjective colour difference (the vertical axis) is the average of 18 comprehensive answers of 6 subjects. The measured and calculated colour difference is very well correlated with the subjective colour difference, the correlation coefficient is 0,91.

The relationship between measured and calculated colour difference on CAM02-UCS that is used to calculate $R_{\mathrm{f}}$ and the subjective colour difference is shown in Figure 11. The measured and calculated colour difference is very well correlated with the subjective colour difference, the correlation coefficient is 0,89 .

Measured and calculated colour difference on both CIE 1964 UCS and CAM02-UCS are well correlated with the subjective colour difference. The reason of the difference of fitting of $R_{\mathrm{a}}$ and $R_{\mathrm{f}}$ with the subjective colour difference cannot be explained from these results. 


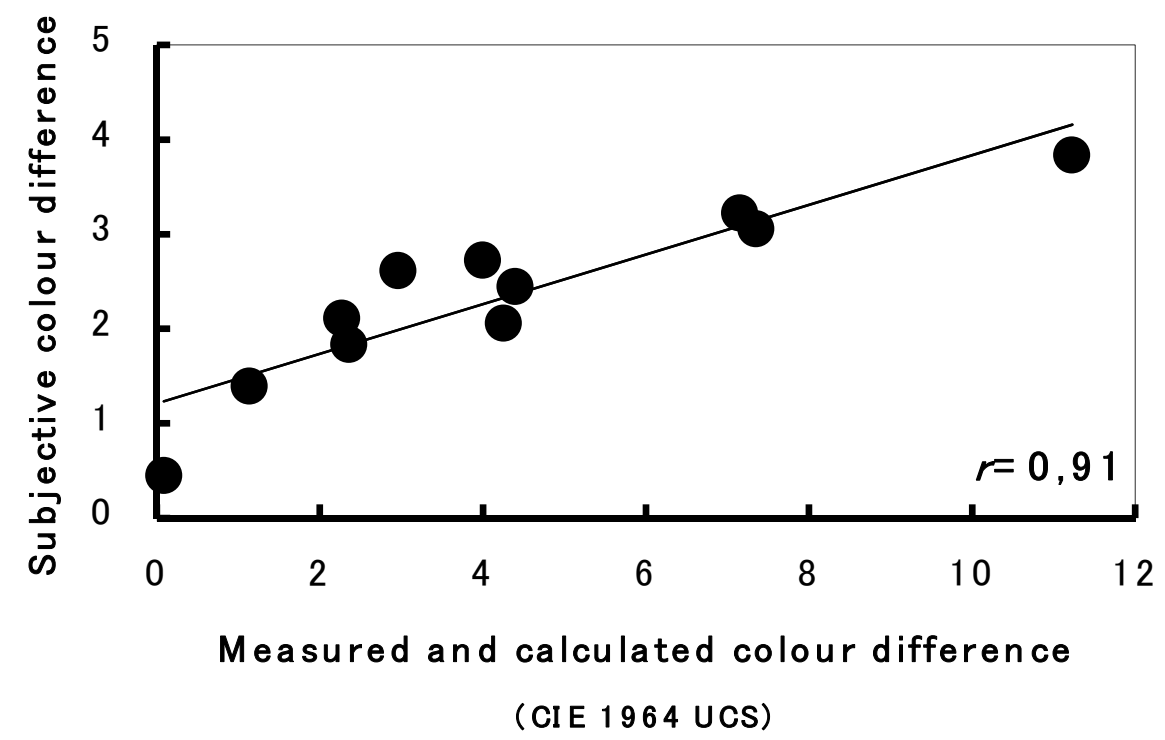

Figure 10 - Relationship between the measured and calculated colour difference on CIE 1964 UCS and the subjective colour difference

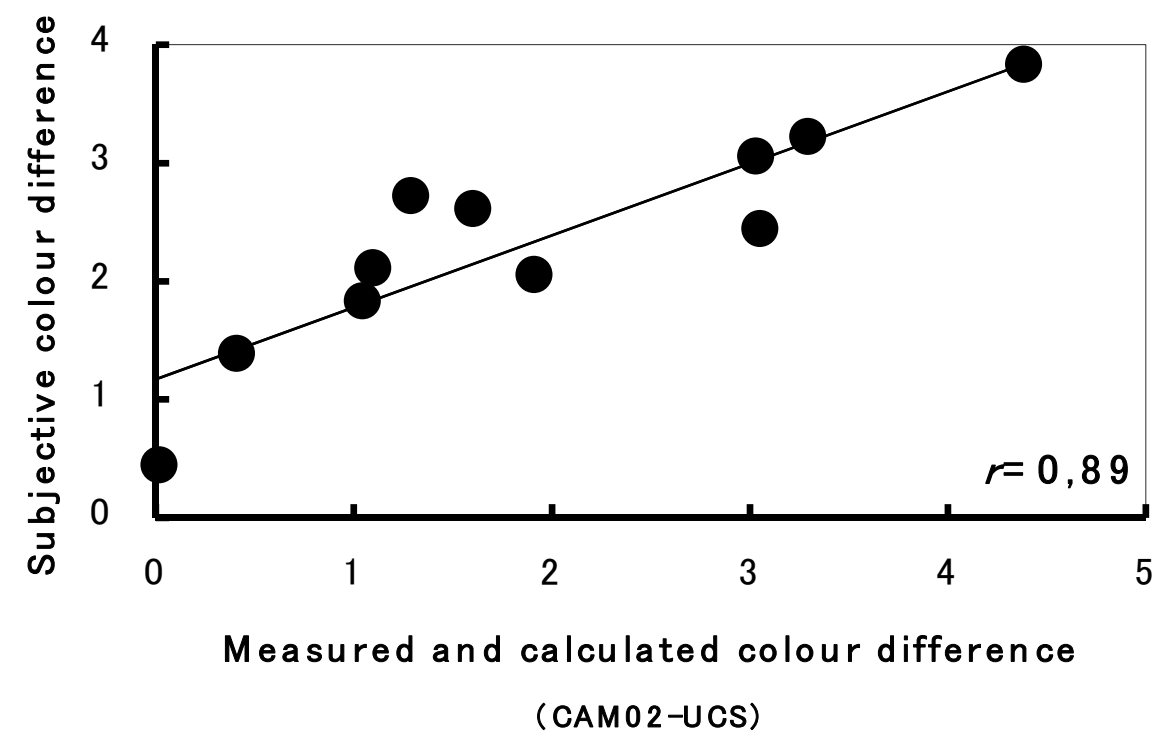

Figure 11 - Relationship between the measured and calculated colour difference on CAM02-UCS and the subjective colour difference

The relationship between measured and calculated colour differences of each 4 test colour sample (red, yellow, green and blue) on CIE 1964 UCS and CAM02-UCS and the subjective colour differences are shown in Figure 12 and 13. Both measured and calculated colour differences and the subjective colour differences are well correlated for each test colour sample. But the slopes of the regression lines are different. 

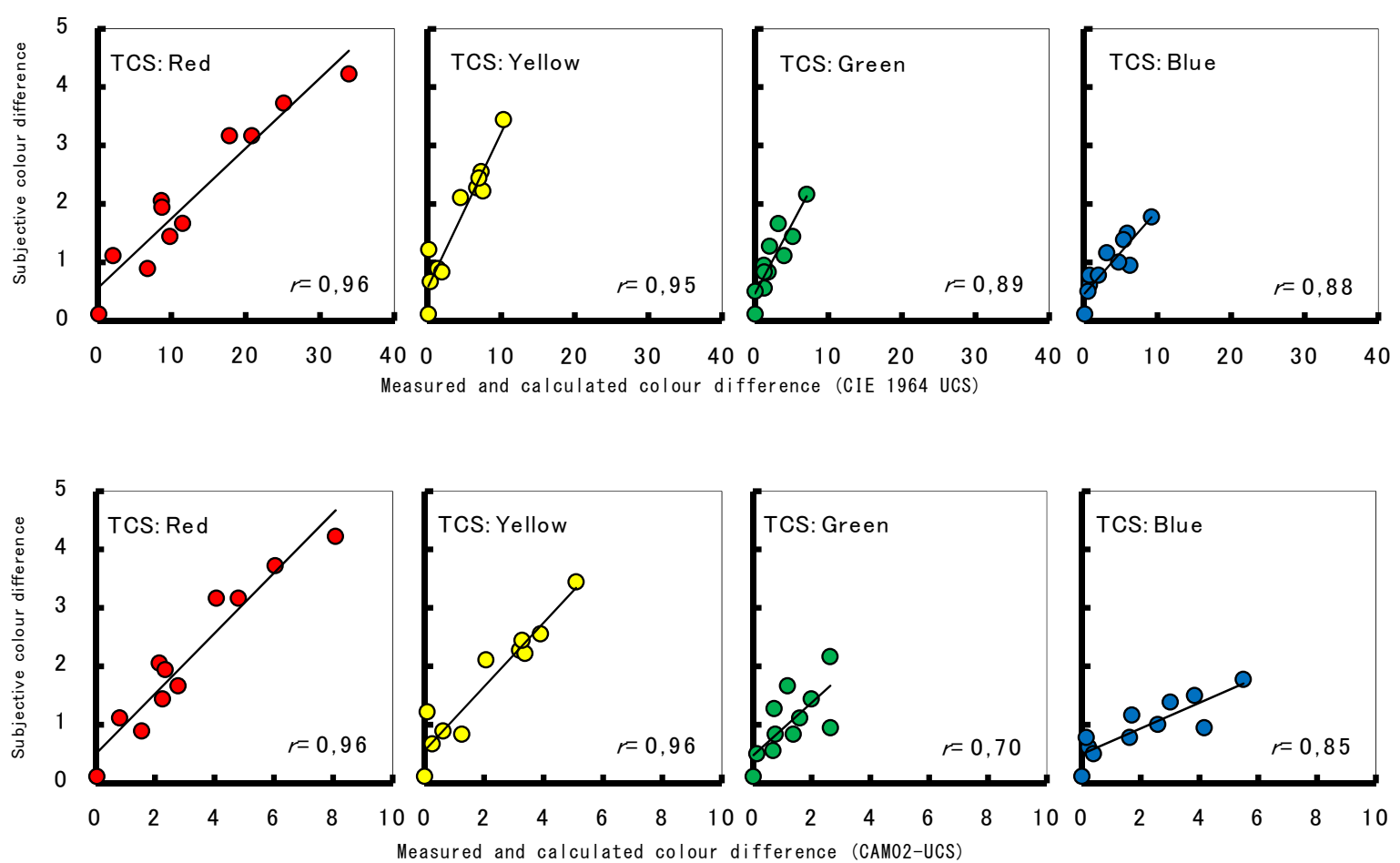

Figure 12 - Relationship between the measured and calculated colour difference of 4 Test Colour Samples

The regression lines between measured and calculated colour differences on the CIE 1964 UCS and the subjective colour differences of 4 TCS are shown in Figure 13. The slope of the line depends on the TCS. The slopes of red and blue sample are lower than yellow and green. That is to say, on CIE 1964 UCS, colour differences of red and blue are calculated larger than subjective colour differences. It is one of the problems of the calculation method of current Colour Rendering Index $R_{\mathrm{a}}$. The regression lines on the CAM02-UCS are shown in Figure 14. The slope of blue is lower than the other 3 colours. That is to say, on CAM02-UCS, colour difference of blue is calculated larger than subjective colour difference. The problem that calculated colour difference of a certain colour is larger than the subjective colour difference is not solved even on the newest uniform colour space.

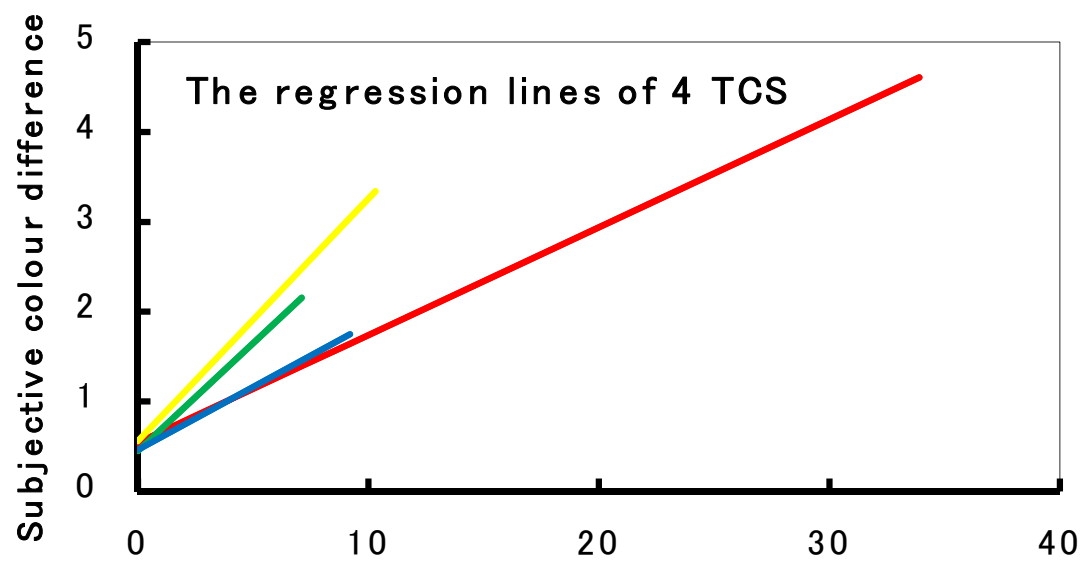

Measured and calculated colour difference

(CIE 1964 UCS)

Figure 13 - The regression lines between measured and calculated colour differences on the CIE 1964 UCS 


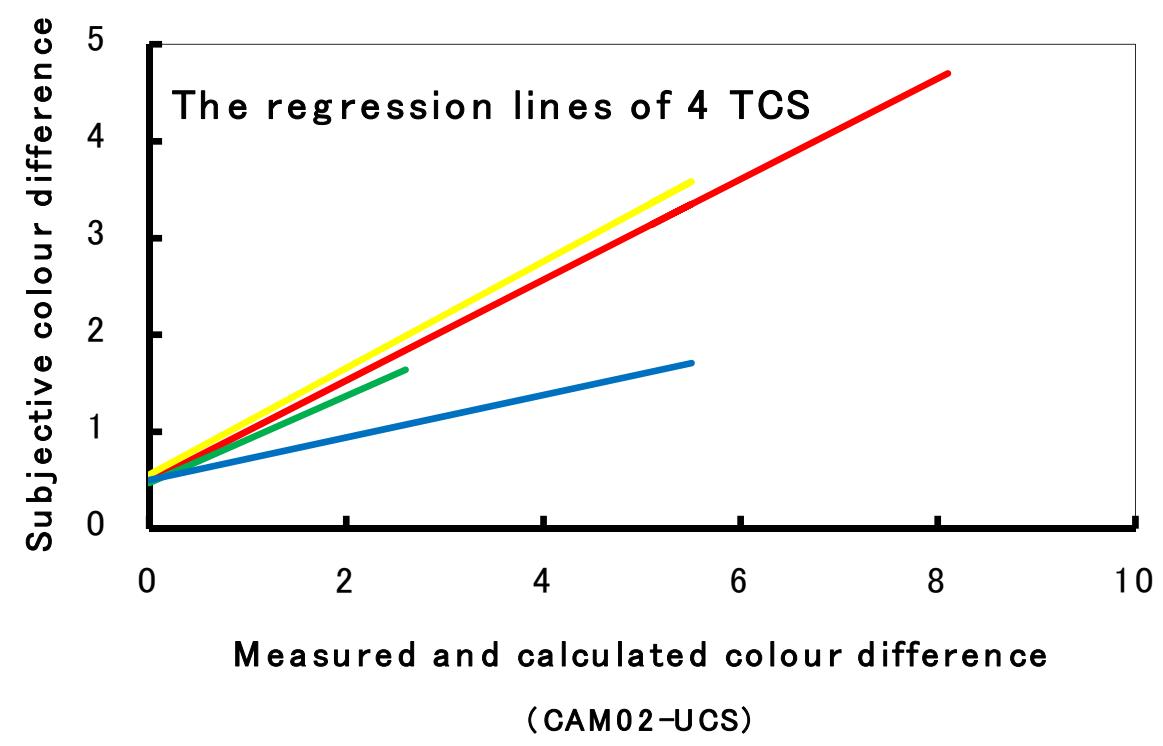

Figure 14 - The regression lines between measured and calculated colour differences on the CAM02-UCS

\section{Conclusion}

A series of experiments was conducted to investigate which Colour Rendering Index, $R_{\mathrm{a}}$ or $R_{\mathrm{f}}$ is well correlated with the subjective colour difference.

The results are summarized below,

- The values of $R_{\mathrm{a}}, R_{\mathrm{f}}$ and the subjective colour difference are in a linear relationship and the larger $R_{\mathrm{a}}, R_{\mathrm{f}}$ are, the smaller the subjective colour differences tend to be.

- The correlation coefficient value between $R_{\mathrm{a}}$ and the subjective colour difference is larger than $R_{\mathrm{f}}$ although there is no significant difference.

- The larger $R_{\mathrm{a}}$ is, the smaller the subjective colour differences tend to be even if $R_{\mathrm{f}}$ is equivalent. On the other hand the subjective colour differences tend to be equivalent if $R_{\mathrm{a}}$ is equivalent even if $R_{\mathrm{f}}$ is different.

- Each calculated colour differences on CIE 1964 UCS and CAM02-UCS is well correlated with the subjective colour differences.

- On CIE 1964 UCS, the calculated colour differences of red and blue are larger than the subjective colour differences. On CAM02-UCS, the calculated colour differences of blue are larger than the subjective colour differences.

From these results, it cannot be concluded which index of $R_{\mathrm{a}}$ and $R_{\mathrm{f}}$ matches the subjective colour difference better. CAM02-UCS matches the colour appearance well but the calculated colour difference on it may not match the small subjective colour difference that is important when considering colour rendering properties. To fit $R_{\mathrm{f}}$ and the subjective colour differences, one solution is to modify the CAM02-UCS to calculate the colour difference of blue lower, another solution is to modify the calculation method of $R_{\mathrm{f}}$ from the calculated colour differences. For example, the calculated colour difference of certain colours may be weighted by using some weighting coefficients. The effect of each subjective colour difference to the comprehensive subjective colour may be different. The magnitude of the influence of each subjective colour difference on the comprehensive subjective colour difference should be studied further. 


\section{References}

SMET, K.A.G. 2016. On the importance of colour space uniformity and sampleset spectral uniformity for colour fidelity measures. Proceedings of CIE 2016 "Lighting Quality and Energy Efficiency". 166-174.

GU, HT. 2017. Testing different colour rendering metrics using colour difference data. Lighting Res. Technol. 49, 539-560.

WEI, M. 2019. Perceived colour fidelity under LEDs with similar $R_{\mathrm{f}}$ but different $R_{\mathrm{a}}$. Lighting Res. Technol. OnlineFirst. 31 Jan 2019. 